\title{
Umidade ponderal em tecidos de pereira durante o período de dormência sob condições de inverno ameno
}

\author{
Anderson Carlos Marafon ${ }^{(1)}$, Flavio Gilberto Herter ${ }^{(2)}$ e Fernando José Hawerroth ${ }^{(3)}$ \\ (1)Embrapa Tabuleiros Costeiros, Unidade de Execução de Pesquisas de Rio Largo, Rodovia BR 104, Km 85, Campus Delza Gitai, \\ Caixa Postal 2013, CEP 57061-970 Rio Largo, AL. E-mail: anderson@cpatc.embrapa.br (2)Universidade Federal de Pelotas, Faculdade \\ de Agronomia Eliseu Maciel, Departamento de Fitotecnia, Campus Universitário, Caixa Postal 354, CEP 96010-900 Pelotas, RS. \\ E-mail: flavioherter@gmail.com ${ }^{(3)}$ Embrapa Agroindústria Tropical, Rua Dra. Sara Mesquita, № 2.270, Planalto do Pici, CEP $60511-110$ Fortaleza, CE. \\ E-mail: fernando@cnpat.embrapa.br
}

\begin{abstract}
Resumo - O objetivo deste trabalho foi avaliar a umidade ponderal (UP) em diferentes tecidos das cultivares de pereira Kieffer (Pyrus communis) e Housui (Pyrus pyrifolia), durante a dormência, em condições de inverno ameno. Foram avaliadas plantas do pomar experimental da Embrapa Clima Temperado, Pelotas, RS. Utilizouse o delineamento experimental inteiramente casualizado, em esquema fatorial $3 \times 4 \times 5$, que consistiu em três tecidos (gema, casca e lenho), quatro porções de ramos (terminal, mediana, axial e esporões) e cinco datas de coleta, em 2005 (1/7, 3/8, 6/9, 23/9 e 13/10), com parcelas subdivididas e três repetições. Houve aumento na UP do lenho na cultivar Kieffer até a metade da dormência, com subsequente redução a partir desta fase, o que pode ser atribuído ao aumento na UP observado nas gemas após satisfação da exigência em frio e superação de dormência. Na cultivar Housui, a insatisfação da exigência em frio, associada à ocorrência de altas temperaturas durante o inverno, refletiu-se na redução da UP e na desidratação das gemas durante a dormência. A dinâmica da água em tecidos de pereira é diretamente influenciada pelo acúmulo de frio hibernal e depende da exigência em frio de cada cultivar.
\end{abstract}

Termos para indexação: Pyrus communis, Pyrus pyrifolia, abortamento floral, brotação, desidratação, exigência em frio.

\section{Water content in pear tree tissues during the dormancy period under mild winter conditions}

\begin{abstract}
The objective of this work was to evaluate the water content (WC) in different tissues of the Kieffer (Pyrus communis) and Housui (Pyrus pyrifolia) pear cultivars during dormancy, under mild winter conditions. Plants from to the experimental orchard of Embrapa Clima Temperado, Pelotas, RS, Brazil, were evaluated. A completely randomized block design, in a $3 \times 4 \times 5$ factorial arrangement, consisting of three tissues (bud, bark and wood), four portions of branches (terminal, median, axial and spurs) and five sampling dates in 2005 (7/1, $8 / 3,9 / 6,9 / 23$ and 10/13), distributed in split-plots, with three replicates, was used. There was a WC increase in the wood of the Kieffer cultivar until the middle of the dormancy period and a subsequent decrease after this phase, which could be attributed to the increase in WC observed in buds after the satisfaction of chilling requirement and dormancy. In the cultivar Housui, unsatisfactory chilling requirement, associated with the occurrence of high temperatures during the winter, reflected in the reduction of WC and in bud dehydration during dormancy. Water dynamics in pear tree tissues is directly influenced by cold accumulation during dormancy period and depends on the cold requirement of each cultivar.
\end{abstract}

Index terms: Pyrus communis, Pyrus pyrifolia, floral bud abortion, budbreak, dehydration, cold requirement.

\section{Introdução}

A pereira (Pyrus spp.) é uma das frutíferas de clima temperado cuja área de plantio ainda não está plenamente desenvolvida no Brasil, principalmente em virtude da falta de cultivares adaptadas às condições de pouco frio hibernal no país (Faoro, 2001).

A dormência consiste em um mecanismo adaptativo das plantas para sobrevivência em condições climáticas adversas e baseia-se na suspensão temporária do crescimento visível de estruturas vegetais contendo um meristema (Samish,1954), como é o caso das gemas das espécies de clima temperado. A dormência pode ser controlada por fatores endógenos (hormonais, nutricionais e genéticos) e exógenos (temperatura, fotoperíodo e disponibilidade de água), em combinação com a redução da atividade metabólica, em que não ocorrem divisões celulares (Faust et al., 1997).

As mudanças na dinâmica da água estão intimamente relacionadas à dormência em espécies lenhosas de clima

Pesq. agropec. bras., Brasília, v.46, n.9, p.1006-1012, set. 2011 
temperado, nas quais a água constitui de 35 a $75 \%$ da massa dos tecidos metabolicamente ativos (Kerbauy, 2008). A disponibilidade e a migração de água são fatores essenciais na compreensão dos mecanismos de ativação do metabolismo envolvido com a retomada do crescimento das gemas na primavera.

A temperatura é o principal fator ambiental que interfere na dinâmica da dormência em gemas de plantas lenhosas de clima temperado, em razão da ação positiva das baixas temperaturas na superação da dormência, o que provoca alterações no estado físico das membranas e no metabolismo enzimático das células, que, consequentemente, influenciam o balanço metabólico da planta (Lang et al., 1987; Crabbé \& Barnola, 1996).

No processo de aclimatação ao frio e indução à dormência das gemas, a água se move dos meristemas apicais mais sensíveis das gemas para os tecidos mais tolerantes ao frio, como as escamas e os tecidos adjacentes do ramo (Yooyongwech et al., 2008). Além de proteger os tecidos contra o congelamento da água, a desidratação celular reduz a atividade metabólica e o consumo de energia das células (Kalberer et al., 2006). $\mathrm{Na}$ fase de superação da dormência, ocorre redução na tolerância ao frio das gemas associada ao aumento no conteúdo de água dos tecidos (Arora et al., 2003).

Durante a fase de dormência, a água pode estar associada a macromoléculas hidrofílicas, e é detectada como água ligada, enquanto, na fase de superação da dormência, encontra-se no seu estado livre (Welling \& Palva, 2006). Estudos de ressonância magnética em gemas de pessegueiro indicam correlação entre os níveis de água ligada e o processo de aclimatação ao frio (Erez et al., 1998) por meio da ativação de dehidrinas, classe de proteínas hidrofílicas, com funções crioprotetoras das membranas e estabilização de macromoléculas, como ácidos nucleicos e proteínas, o que evita a sua desnaturação (Wisniewski et al., 2006).

Em condições de dias curtos e baixas temperaturas, a maior parte da água encontrada em gemas de macieira está na sua forma agregada (ligada a macromoléculas) e é liberada gradualmente, durante a dormência, e rapidamente, na fase de brotação, a partir da aplicação de indutores ou em condições de forçagem. Quando a água encontra-se ligada, não ocorrem aumentos consideráveis no tamanho das gemas; no entanto, no final da dormência, quando cerca de dois terços da água já está no estado livre, ocorre aumento considerável no tamanho das gemas, mesmo sem nenhum sinal visível de brotação (Buban \& Faust, 1995).

$\mathrm{O}$ transporte de água entre células durante a dormência pode ser restringido pelo bloqueio dos plasmodesmas, causado pela deposição de cálcio ou 1-3- $\beta$-glucano. Em condições de acúmulo de frio suficiente, o plasmodesma readquire normalmente a sua capacidade de transportar água, íons, nucleotídeos e pequenos metabólitos, como aminoácidos e açúcares. Entretanto, em situações de falta de frio, a comunicação entre as células via simplasto não se reestabelece perfeitamente, o que resulta em irregularidades na brotação (Rinne et al., 2001).

O objetivo deste trabalho foi avaliar a umidade ponderal (UP) em diferentes tecidos das cultivares de pereira Kieffer e Housui, durante a dormência, em condições de inverno ameno.

\section{Material e Métodos}

O experimento foi conduzido em pomar da Embrapa Clima Temperado, Pelotas, RS $\left(31^{\circ} 41^{\prime} \mathrm{S}, 52^{\circ} 26^{\prime} \mathrm{W}\right)$. O clima da região, segundo Köppen, é do tipo Cfa, subtropical úmido, com médias anuais de $1.582 \mathrm{~mm}$ de precipitação, $18,4^{\circ} \mathrm{C}$ de temperatura e $78 \%$ de umidade relativa do ar. $\mathrm{O}$ acúmulo de horas de frio $\left(\mathrm{HF} \leq 7,2^{\circ} \mathrm{C}\right)$ durante a execução do experimento foi de $231 \mathrm{HF}$, valor inferior à média histórica para o local, que é de 348 HF (1984 a 2009), conforme dados fornecidos pelo Laboratório de Agrometeorologia da Embrapa Clima Temperado.

Foram avaliados três tecidos (gema, casca e lenho), em quatro porções de ramos (terminal, mediana, axial e esporões), das cultivares de pereira Kieffer (Pyrus communis L.) e Housui [Pyrus pyrifolia (Burm. f.) Nakai], coletados em cinco épocas (1/7, 3/8, 6/9, 23/9 e 13/10) durante o inverno de 2005. A cultivar Kieffer apresenta baixa exigência em horas de frio (300 HF), além de baixos índices de abortamento floral, enquanto a cultivar Housui apresenta exigência média (700 HF) e índices de abortamento próximos a $100 \%$, na maioria dos anos (Faoro, 2001).

As amostras foram coletadas e pesadas em balança analítica de precisão, para obtenção da massa fresca (MF). Em seguida, as amostras foram secas em estufa a $70^{\circ} \mathrm{C}$ sob ventilação forçada, até atingir massa constante, e foram pesadas novamente para registro da massa seca (MS). A UP foi determinada por meio

Pesq. agropec. bras., Brasília, v.46, n.9, p.1006-1012, set. 2011 
da fórmula: $\mathrm{UP}=(\mathrm{MF}-\mathrm{MS}) / \mathrm{MS}$. O teor de água (\%) foi representado pela razão entre massa fresca e massa seca e expresso em função da matéria fresca. Já a UP (conteúdo de água), correspondeu ao volume de água celular expressa em função da massa seca e não foi influenciada por variações na matéria seca dos tecidos.

Utilizou-se o delineamento experimental inteiramente casualizado, em esquema fatorial triplo $3 \times 4 \times 5$, com parcelas subdivididas e três repetições. Os fatores experimentais foram: tecidos (três), porções do ramo (quatro) e datas de coleta (cinco). As médias da UP foram comparadas entre tecidos dentro da mesma porção de ramo e entre porções do ramo dentro do mesmo tipo de tecido. Para comparação das médias, utilizou-se o teste de Tukey, a 5\% de probabilidade, com uso do programa estatístico WinStat (Machado \& Conceição, 2003).

\section{Resultados e Discussão}

Houve interação significativa entre os fatores época, tecido e porção do ramo para os valores da UP, em ambas as cultivares avaliadas (Tabela 1). Em todas as coletas, a casca apresentou os maiores valores para UP, em comparação aos demais, com tendência de aumento a partir da metade do inverno, nas duas cultivares (Figura 1).

$\mathrm{Na}$ cultivar Kieffer, a UP das gemas apresentou redução no início do inverno, em todas as porções de ramos, exceto na basal, além de considerável aumento na fase que antecede a brotação, a partir da penúltima coleta, em 23/9. A UP do lenho apresentou aumentos

Tabela 1. Resumo da análise de variância para umidade ponderal em tecidos das cultivares de pereira Housui e Kieffer, durante o período de dormência, no inverno de 2005.

\begin{tabular}{lccc}
\hline Fonte de variação & GL & \multicolumn{2}{c}{ Quadrado médio } \\
\cline { 3 - 4 } & & 'Housui' & 'Kieffer' \\
\hline Tecido (T) & 2 & $10,258^{* *}$ & $13,136^{* *}$ \\
Porção do ramo (P) & 3 & $0,039^{*}$ & $0,184^{* *}$ \\
Época (E) & 4 & $0,047^{*}$ & $0,364^{* *}$ \\
T x P & 6 & $0,267^{* *}$ & $0,187^{* *}$ \\
T x E & 8 & $0,121^{* *}$ & $0,284^{* *}$ \\
P x E & 12 & $0,070^{* *}$ & $0,037^{* *}$ \\
T x P x E & 24 & $0,025^{*}$ & $0,024^{*}$ \\
Resíduo & 240 & 0,014 & 0,013 \\
\hline Média & & 1,21 & 1,15 \\
CV (\%) & & 9,85 & 10,03 \\
\hline
\end{tabular}

$* \mathrm{e} * *$ Significativo pelo teste $\mathrm{F}$, a 5 e $1 \%$ de probabilidade, respectivamente. gradativos até a terceira coleta (6/9) e reduções subsequentes nas duas últimas coletas (23/9 e 13/10), em todas as porções, exceto na basal, na qual se manteve estável.

Os aumentos na UP do lenho até a metade do período de inverno representam o aumento do volume de seiva xilemática, que pode ser atribuído à migração de água e açúcares solúveis das células de reserva do parênquima ao xilema. $\mathrm{O}$ aumento na UP das gemas no final do período de dormência pode ser explicado pelas reduções nos valores da UP do lenho, que se refletiriam na movimentação da seiva do xilema em direção às gemas, para induzir a brotação no início da primavera.

A redução no conteúdo de água dos tecidos meristemáticos é fator fundamental para aumentar a concentração de solutos e reduzir o ponto de congelamento das células, o que torna esta estrutura resistente ao frio. Durante a fase de aclimatação ao frio e indução da dormência em gemas florais de macieira, os vacúolos se tornam menores em virtude do acúmulo de moléculas hidrofílicas localizadas no citoplasma, como açúcares e dehidrinas, que alteram o potencial osmótico e a disponibilidade de água nas células meristemáticas (Kuroda \& Sagisaka, 2001).

A reidratação das células meristemáticas das gemas ocorre somente nas gemas que vão brotar efetivamente, e, em geral, tem início um mês antes dos primeiros sinais de brotação. $\mathrm{O}$ aumento considerável na UP das gemas da cultivar Kieffer, no final do período de dormência, indica que o estado de hidratação das gemas tem forte relação com o aumento da atividade metabólica e com os processos de superação da dormência e, consequentemente, com a capacidade de brotação das gemas. Cronjé et al. (2003) observaram que o conteúdo de água em gemas de macieira foi de $41 \%$ durante a dormência e que aumentou para $59 \%$ no início da brotação. Cottignies (1990) verificou que o aumento no potencial hídrico e osmótico da seiva xilemática, uma semana antes da brotação, possibilitou a reativação do metabolismo e induziu a brotação em gemas terminais de plantas de freixo (Fraxinus excelsior L.), no início da primavera.

A seiva do xilema tem sido considerada como a principal via de transporte de açúcares dos tecidos de reserva para as gemas, na fase de superação da dormência em macieira, nogueira e cerejeira (Loescher et al., 1990; Ameglio et al., 2001). Essiamah \& Eschrich (1985) observaram correlação positiva entre 

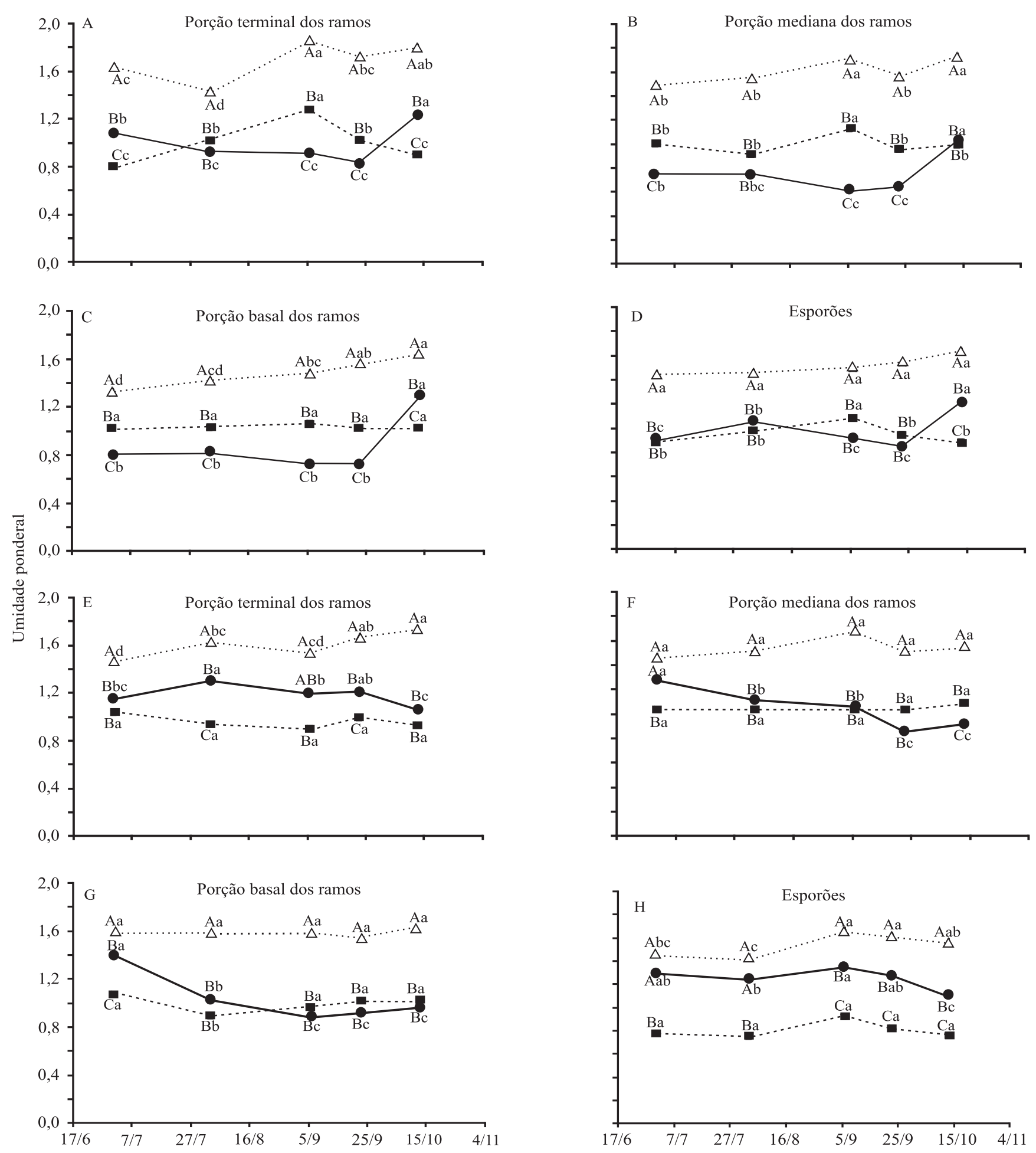

Data de avaliação

$\longrightarrow$ Tecidos da gema $\cdots \Delta \cdots \cdot$ Tecidos da casca $\quad--\mathbf{m - -}$ Tecidos do lenho

Figura 1. Umidade ponderal em diferentes tecidos e porções de ramos das cultivares de pereira Kieffer (A a D) e Housui (E a H), durante o período de dormência, no inverno de 2005. Médias seguidas de letras iguais, maiúsculas na mesma data e minúsculas no mesmo tecido, não diferem pelo teste de Tukey, a 5\% de probabilidade. 
a dissolução do amido do parênquima e o volume de seiva xilemática, em espécies decíduas do hemisfério Norte durante a primavera, o que indica processo de interconversão amido $\mathrm{x}$ açúcares solúveis.

A diferença de pressão gerada entre os vasos do xilema (apoplasto) e o parênquima (simplasto) pressupõe que o movimento de água e de solutos ocorre em razão do gradiente de potencial osmótico entre a seiva e as células de transferência do xilema, conectadas às células do parênquima. Essa pressão provavelmente ocorre pelo acúmulo de açúcares e íons na seiva, em função da atividade de $\mathrm{H}^{+}$-ATPases, bombas de prótons, aquaporinas, canais iônicos e cotransportadores especializados no influxo e efluxo de solutos, situados na membrana plasmática das células de transferência (De Boer \& Volkov, 2003).

$\mathrm{O}$ efeito das baixas temperaturas sobre o aumento dos açúcares solúveis pode explicar os altos valores do potencial osmótico da seiva do xilema de plantas lenhosas de clima temperado, durante o inverno. Os açúcares solúveis respondem por cerca de $60 \%$ do potencial hídrico da seiva xilemática e direcionam osmoticamente a água das fibras e das células parenquimáticas para os vasos do xilema (Ameglio et al., 2001). Durante o inverno, o frio não exerce efeito sobre a atividade das $\mathrm{H}^{+}$-ATPases das células de transferência do xilema; entretanto, no início da primavera, após a satisfação da exigência em frio das plantas, ocorrem aumentos na atividade dessas enzimas para a geração de um gradiente de prótons favorável à absorção de açúcares solúveis da seiva do xilema para as gemas. As plantas mantidas sob privação de frio $\left(15^{\circ} \mathrm{C}\right)$ apresentam alta atividade de $\mathrm{H}^{+}$-ATPases durante a dormência, o que provoca alto consumo de energia e resulta em brotação irregular (Alves et al., 2004).

As gemas da porção terminal dos ramos e dos esporões da cultivar Kieffer apresentaram valores significativamente superiores para UP, em comparação às demais porções dos ramos. Quanto aos tecidos da casca e do lenho, foram observadas diferenças significativas entre as porções de ramos avaliadas (Figura 1). $\mathrm{O}$ aumento na massa fresca das gemas na fase que antecede a brotação, em virtude do aumento na importação de água e solutos, promove a reidratação e possibilita a ativação do metabolismo das gemas (Essiamah \& Eschrich, 1986).
$\mathrm{Na}$ cultivar Housui, houve pequenas variações na UP dos tecidos da casca e do lenho, além de aumentos na UP da casca dos esporões e da porção terminal na terceira e quarta coletas, respectivamente. A UP das gemas apresentou redução significativa a partir da segunda coleta na porção basal e mediana dos ramos, tendo atingido valores muito baixos na última coleta. Também foram observadas reduções significativas na UP das gemas dos esporões e da porção terminal dos ramos na quarta e quinta coletas, respectivamente.

A exigência de frio da cultivar Kieffer foi plenamente satisfeita no ano de execução deste experimento, o que possibilitou a mobilização de nutrientes e água para a nutrição e a retomada de crescimento das gemas. No entanto, a cultivar Housui não teve sua necessidade de frio satisfeita e, provavelmente, por isso não apresentou aumento na UP (hidratação) das gemas para a retomada do crescimento, o que resultou em altos índices de abortamento de gemas florais.

Não houve reduções significativas na UP do lenho para as diferentes porções do ramo da cultivar Housui, como foi observado para Kieffer. Isso indica que não houve migração de água e de solutos para os vasos do xilema ou aumento do gradiente de pressão osmótica da seiva, o que permitiria a movimentação da seiva xilemática em direção aos primórdios das gemas para a retomada do seu crescimento. Consequentemente, houve reduções na UP das gemas nas últimas coletas, o que causaria desidratação e necrose dos primórdios florais.

O abortamento floral manifesta-se durante a dormência e intensifica-se próximo à fase de floração. As gemas apresentam desenvolvimento normal no início do inverno, quando ocorre intensa necrose dos primórdios florais próximo à fase de brotação. A incidência do abortamento pode estar relacionada à falta de frio e à ocorrência de altas temperaturas durante a dormência, já que o problema é menor em regiões mais frias (Petri et al., 2002).

Quanto às diferentes porções de ramos avaliadas na cultivar Housui, observou-se que as gemas terminais e as dos esporões apresentaram os maiores valores para UP (Figura 1). As gemas situadas nos ápices dos ramos apresentaram maior grau de hidratação, o que provavelmente explica porque essas gemas foram as últimas a sofrer a dessecação dos primórdios florais e a apresentar sintomas de necrose dos tecidos (Marafon et al., 2010). 
A reidratação das gemas envolve, necessariamente, a geração de potencial de pressão no ramo, ocasionado pelo efluxo de açúcares solúveis das células parenquimáticas, que atrairá osmoticamente a água para dentro dos vasos do xilema durante o processo de mobilização de reservas. Segundo Leite (2004), a reidratação das gemas ocorre, em geral, um mês antes da brotação, associada à mobilização do amido e ao deslocamento da água junto com os açúcares solúveis. A aceleração do crescimento das gemas se manifesta após a superação da endodormência, por meio da redução e da estabilização dos valores do tempo médio de brotação, obtido pelo "teste de estacas de nós isolados", com aumento no conteúdo de água nas gemas.

A ocorrência do abortamento floral pode ser atribuída à incapacidade de importação de carboidratos pelas gemas, associada ao baixo metabolismo enzimático, o que resulta na exaustão das reservas nutricionais nos primórdios florais (Bonhomme et al., 2005). As altas temperaturas aumentam a atividade respiratória e a demanda energética das gemas, o que consome as reservas locais de carboidratos para manutenção do metabolismo basal dos tecidos meristemáticos. Portanto, ocorre desidratação das gemas e exaurimento das reservas de nutrientes, com consequente surgimento dos sintomas de necrose nos primórdios florais (Marafon, 2008).

Yamamoto et al. (2010) relataram que gemas de pereira-japonesa submetidas a baixas temperaturas apresentaram baixa mobilidade e baixo conteúdo de água (UP) durante a dormência, com gradual incremento nas taxas de água livre na fase de superação da dormência. Contudo, aumentos abruptos na mobilidade e na UP foram constatados na base das gemas e nos primórdios florais durante a dormência das plantas privadas de frio, o que resultou na necrose dos primórdios florais. Assim, a desidratação das gemas florais da cultivar Housui, ocasionada pela falta de frio, provocaria o esgotamento de carboidratos e o acúmulo destes nutrientes na base das gemas, os quais seriam realocados para o desenvolvimento de novas inflorescências.

\section{Conclusões}

1. A dinâmica da água em tecidos de pereira é diretamente influenciada pelo acúmulo de frio hibernal e depende da exigência em frio de cada cultivar.
2. A migração de água para as gemas é essencial para a sua reidratação e a retomada do crescimento no início da primavera.

3. Quando a exigência em frio da cultivar Kieffer é satisfeita, ocorre migração de água dos tecidos lenhosos para reidratação das gemas na fase de superação de dormência; já na cultivar Housui, que apresenta média necessidade em frio, ocorre desidratação dos primórdios quando o acúmulo de baixas temperaturas $\left(\leq 7,2^{\circ} \mathrm{C}\right)$ é insuficiente durante a dormência.

4. A umidade ponderal dos tecidos é importante indicador fisiológico do nível de hidratação e da atividade metabólica de células e organelas e pode servir como marcador da fase de superação da endodormência, antes do surgimento dos primeiros sinais visíveis de brotação.

\section{Agradecimentos}

Ao Conselho Nacional de Desenvolvimento Científico e Tecnológico e à Coordenação de Aperfeiçoamento de Pessoal de Nível Superior, pelo apoio financeiro; e à Embrapa Clima Temperado, pela disponibilização de infraestrutura, reagentes e pessoal de apoio.

\section{Referências}

ALVES, G.;AMÉGLIO, T.; GUILLIOT, A.; FLEURAT-LESSARD, P.; LACOINTE, A.; SAKR, S.; PETEL, G.; JULIEN, J. Winter variation in xylem sap $\mathrm{pH}$ of walnut trees: involvement of plasma membrane $\mathrm{H}^{+}$-ATPase of vessel-associated cells. Tree Physiology, v.24, p.99-105, 2004.

AMEGLIO, T.; EWERS, F.W.; COCHARD, H.; MARTIGNAC, M.; VANDAME, M.; BODET, C.; CRUIZIAT, P. Winter stem xylem pressure in walnut trees: effects of carbohydrates, cooling and freezing. Tree Physiology, v.21, p.387-394, 2001.

ARORA, R.; ROWLAND, L.J.; TANINO, K. Induction and release of bud dormancy in woody perennials: a science comes of age. HortScience, v.38, p.911-921, 2003.

BONHOMME, M.; RAGEAU, R.; LACOINTE, A.; GENDRAUD, $M$. Influences of cold deprivation during dormancy on carbohydrate contents of vegetative and floral primordia and nearby structures of peach buds (Prunus persica L. Batch). Scientia Horticulturae, v.105, p.223-240, 2005.

BUBAN, T.; FAUST, M. New aspects of bud dormancy in apple trees. Acta Horticulturae, n.395, p.105-109, 1995.

COTTIGNIES, A. Potentiel osmotique et potentiel hydrique du bourgeon terminal de Frenê, au cours du cycle annuel. Comptes Rendus de L'académie des Sciences, v.310, p.211-216, 1990.

CRABBÉ, J.; BARNOLA, P.A. New conceptual approach to bud dormancy in woody plants. In: LANG, G.A. (Ed.). Plant 
dormancy: physiology, biochemistry and molecular biology. Wallingford: CAB International, 1996. p.83-113.

CRONJÉ, P.J.R.; JACOBS, G.; SADIE, A.; COOK, N.C. Quantification of the dormancy progression in terminal apple buds. Changes in growth rate and water status. Advances in Horticultural Science, v.17, p.105-110, 2003.

DE BOER, A.H.; VOLKOV, V. Logistics of water and salt transport through the plant: structure and functioning of the xylem. Plant Cell and Environment, v.26, p.87-101, 2003.

EREZ, A.; FAUST, M.; LINE, M.J. Changes in water status in peach buds on induction, development and release from dormancy. Scientia Horticulturae, v.73, p.111-123, 1998.

ESSIAMAH, S.K.; ESCHRICH, W. Changes of starch content in the storage tissues of deciduous trees during winter and spring. IAWA Bulletin, v.6, p.97-106, 1985.

ESSIAMAH, S.K.; ESCHRICH, W. Water uptake in deciduous trees during winter and the role of conducting tissues in spring reactivation. IAWA Bulletin, v.7, p.31-38, 1986.

FAORO, I.D. Morfologia e fisiologia. In: NASHI: a pêra japonesa. Florianópolis: Epagri, 2001. p.67-94.

FAUST, M.; EREZ, A.; ROWLAND, L.J.; WANG, S.Y.; NORMAN, H.A. Bud dormancy in perennial fruit trees: physiological basis for dormancy induction, maintenance, and release. HortScience, v.32, p.623-629, 1997.

KALBERER, S.R.; WISNIEWSKI, M.;ARORA, R. Deacclimation and reacclimation of cold-hardy plants: current understanding and emerging concepts. Plant Science, v.171, p.3-16, 2006.

KERBAUY, G.B. Fisiologia vegetal. 2.ed. Rio de Janeiro: Guanabara Koogan, 2008. 431p.

KURODA, H.; SAGISAKA, S. Ultrastructural changes in apical meristem cells of apple flower buds associated with dormancy and cold tolerance. Journal of the Japanese Society for Horticultural Science, v.70, p.553-560, 2001.

LANG, G.A.; EARLY, J.A.; MARTIN, G.C.; DARNELL, R.L. Endodormancy, paradormancy and ecodormancy: physiological terminology and classification for dormancy research. HortScience, v.22, p.371-377, 1987.

LEITE, G.B. Evolution des états des bourgeons et de leur hétérogénéité le long du rameau d'un an de pêcher sous différents régimes de températures après l'installation de l'endodormance. 2004. 159p. Thèse (Doctorat) - Université Blaise Pascal, Clermont-Ferrand.
LOESCHER, W.H.; MCCAMANT, T.; KELLER, J.D. Carbohydrate reserves, translocation, and storage in woody plant roots. HortScience, v.25, p.274-281, 1990.

MACHADO, A.A.; CONCEIÇÃO, A.R. WinStat: sistema de análise estatística para Windows. Versão 2.11. Pelotas: Universidade Federal de Pelotas, 2003.

MARAFON, A.C. Metabolismo de carboidratos, conteúdo de água e necrose floral em pereira (Pyrus sp.) em condições de falta de frio. 2008. 80p. Tese (Doutorado) - Universidade Federal de Pelotas, Pelotas.

MARAFON, A.C.; HAWERROTH, F.J.; HERTER, F.G. Ocorrência e intensidade de necrose floral em gemas de pereira japonesa cv. Housui durante o período de inverno. Revista Agropecuária Catarinense, v.23, p.64-69, 2010.

PETRI, J.L.; LEITE, G.B.; YASUNOBU, Y. Studies on the causes of floral bud abortion of japanese pear (Pyris pyrifolia) in Southern Brazil. Acta Horticulturae, n.587, p.375-380, 2002.

RINNE, P.L.H.; KAIKURANTA, P.M.; SCHOOT, C. van der. The shoot apical meristem restores its symplasmic organization during chilling-induced release from dormancy. Plant Journal, v.26, p.249-264, 2001

SAMISH, R.M. Dormancy in woody plants. Annual Review of Plant Physiology, v.5, p.183-204, 1954.

WELLING, A.; PALVA, E.T. Molecular control of cold acclimation in trees. Physiologia Plantarum, v.127, p.167-181, 2006.

WISNIEWSKI, M.E.; BASSETT, C.L.; RENAUT, J.; FARRELL J.R.; TWORKOSKI, T.; ARTLIP, T.S. Differential regulation of two dehydrin genes from peach (Prunus persica) by photoperiod, low temperature and water deficit. Tree Physiology, v.26, p.575-584, 2006.

YAMAMOTO, R.R.; HORIGANE, A.K.; YOSHIDA, M.; SEKOZAWA, Y.; SUGAYA, S.; GEMMA, H. "Floral primordia necrosis" incidence in mixed buds of japanese pear (Pyrus pyrifolia (burm.) Nakai var. culta) 'Housui' grown under mild winter conditions and the possible relation with water dynamics. Journal of Japanese Society for the Horticultural Science, v.79, p.246-257, 2010.

YOOYONGWECH, S.; HORIGANE, A.K.; YOSHIDA, M.; YAMAGUCHI, M.; SEKOZAWA, Y.; SUGAYA, S.; GEMMA, $\mathrm{H}$. Changes in aquaporin gene expression and magnetic resonance imaging of water status in peach tree flower buds during dormancy. Physiologia Plantarum, v.134, p.522-533, 2008.

\footnotetext{
Recebido em $1^{\circ}$ de maio de 2011 e aprovado em 2 de setembro de 2011
} 